\title{
BMJ Open Cross-sectional study of Australian medical student attitudes towards older people confirms a four-factor structure and psychometric properties of the Australian Ageing Semantic Differential
}

\author{
Mark Wilson (D) ,1,2 Yvonne Tran (D) , ${ }^{3}$ Ian Wilson, ${ }^{1}$ Susan E Kurrle ${ }^{4,5}$
}

To cite: Wilson M, Tran Y, Wilson I, et al. Cross-sectional study of Australian medical student attitudes towards older people confirms a four-factor structure and psychometric properties of the Australian Ageing Semantic Differential. BMJ Open 2020;10:e036108. doi:10.1136/ bmjopen-2019-036108

- Prepublication history and additional material for this paper are available online. To view these files, please visit the journal online (http://dx.doi. org/10.1136/bmjopen-2019036108).

Received 08 December 2019 Revised 11 May 2020 Accepted 14 July 2020

Check for updates

(c) Author(s) (or their employer(s)) 2020. Re-use permitted under CC BY-NC. No commercial re-use. See rights and permissions. Published by BMJ.

For numbered affiliations see end of article.

Correspondence to

Dr Mark Wilson;

markw@uow.edu.au

\section{ABSTRACT}

Objectives The Australian Ageing Semantic Differential (AASD) survey was developed to quantify medical student attitudes towards older people. The purpose of this study is to examine psychometric properties of the survey and confirm its factor structure of four composites.

Design A cross-sectional study.

Setting Three medical schools in three Australian states: Victoria, Western Australia and South Australia.

Participants Third-year or fourth-year medical students $(n=188$, response rate $=79 \%)$.

Outcome measures In the previous AASD study, exploratory factor analysis supported a four-factor model consisting of 'Instrumentality' (I), 'Personal Appeal' (PA), 'Experience' (E) and 'Sociability' (S). Congeneric one-factor confirmatory factor analysis (CFA) were used to examine model fit for factors using a new student sample $(n=188)$. Psychometric properties of survey items and factors. Post-hoc analysis of pooled data from this study and earlier AASD study ( $n=509)$.

Results Indices of fit (Comparative Fit Index (CFI), TuckerLewis Index (TLI), root mean square error of approximation (RMSEA), standardised root mean square residual (SRMR)) for data to the factor model were: PA adequate fit (CFI=0.94, $\mathrm{TLI}=0.89, \mathrm{RMSEA}=0.11$ and $\mathrm{SRMR}=0.05$ ), I good fit (CFI=0.99, TLI=0.99, RMSEA $=0.04$ and SRMR=0.03), $\mathrm{S}$ good fit $(\mathrm{CFI}=0.98, \mathrm{TLI}=0.95, \mathrm{RMSEA}=0.06$ and $S R M R=0.03)$ and $E$ excellent fit $(C F I=1.0, T L I=1.0$, RMSEA $=0.00$ and SRMR $=0.01$ ).

The AASD was internally consistent (Cronbach's alpha $=0.84$ ), without difference in mean student scores by institution. Mean AASD score was positive for medical students outside New South Wales (73.2/114).

Mean I score for all Australian students was negative, with female respondents' mean E score significantly higher than their counterparts. A positive correlation between student age and I score was noted.

Conclusions The AASD is internally consistent and generalisable within Australia, with acceptable structural validity for measuring medical student attitudes towards older people within a four-factor model. Student attitudes were positive globally and within all factors except I. Female students rated older persons E more positively. Older students recorded more positive attitudes towards I of older people.
Strengths and limitations of this study

- The study outlines psychometric properties of the Australian Ageing Semantic Differential (AASD), a recently developed instrument for quantifying Australian medical student attitudes towards older people.

- Confirmatory factor analysis of new medical student AASD survey data, obtained in three other states of Australia outside the state where the instrument was originally developed, was used to test structural validity of the original four-factor model.

- Statistical analysis of pooled AASD survey data from first-year, third-year and fourth-year students from six Australian medical schools in four states provides evidence for generalisability of the instrument within Australia, and insights into attitudes of Australian medical students towards older people.

- As this study makes use of AASD survey of a convenience sample of students from 6 of 19 medical schools in Australia, a more comprehensive study in future may result in evolution of the factor model for student attitudes towards older people.

- As this has been a cross-sectional study, any demographic trends for student attitudes observed will need to be clarified by further research.

\section{INTRODUCTION}

Attitudes towards older people will drive clinical practice. In 2012, an opinion piece entitled 'Time to end ageism in medical education' was written by a Canadian medical student. ${ }^{1}$ We echo this call for change, and believe that a better understanding of Australian medical students' attitudes, assisted by quantitative, qualitative and mixed methodology research, will help direct medical curriculum innovations designed to foster optimal medical graduate attitudes towards older people. Optimisation of medical practitioner attitudes will reduce the effects of ageism extant in the current Australian healthcare 
system. This paper describes a study designed to confirm the factor structure of the Australian Ageing Semantic Differential (AASD), a novel survey instrument developed as the result of identifying the need for a modern, 'fit for purpose' measure of Australian medical student attitudes towards older people. The study was also critical in order to demonstrate generalisability of the AASD across medical schools within Australia, as hitherto the instrument had only been employed in New South Wales (NSW), where it was recently developed.

The Australian Human Rights Commission advocates for human rights training of health workers to improve health service delivery for the aged:

'...delivered in a manner that is non-discriminatory and promotes equality; ensures that services are available, accessible, appropriate and of good quality'.2 (p1)

Medical student attitudes will naturally reflect those of wider society, with ageist views widespread across cultures. ${ }^{3}$ Older people may feel patronised, struggle with accessing health and other community services, and may feel marginalised from the community because of age discrimination. ${ }^{4}$ Societal stereotyping explains why even first year medical students have been reported to have negative attitudes towards older people. ${ }^{5}$

In addressing societal stereotypes around age, medical curricula need to evolve in order that their structure and context do not unintentionally engender in students negative attitudes towards older people. Medical courses are grounded in specialty hospital rotations with inpatient demographics skewed towards older and sicker people, often perceived by students as complex to assess and treat, more fragile and having communication difficulty. ${ }^{6}$ Unsurprisingly, longitudinal deterioration in attitudes towards older people during medical training has been described. ${ }^{7}$ Younger people often view physical loss of function with age as normative. ${ }^{8}$ Medical students need reminding during training that the majority of Australians over 65 years of age feel they have good, very good or excellent health. ${ }^{9}$

Role modelling by clinical teachers via the 'hidden curriculum' shapes medical student professional development. ${ }^{10}$ Ageist stereotypes are displayed by doctors during some interactions with older patients. ${ }^{11}$ While a positive trend for Australian medical practitioner attitudes towards older people has been quantified, ${ }^{12}$ one qualitative study has revealed Australians may perceive age discrimination within the healthcare system. ${ }^{13}$ An example of systemic discrimination is the dwindling proportion of general practitioners (GPs) treating older people in aged care facilities (ACF), with half or fewer prepared to take on this role. ${ }^{14}{ }^{15} \mathrm{~A}$ recent Australian Medical Association's member survey found that over one-third of doctors surveyed planned to stop taking new patients in ACF, to reduce the number of visits or to stop ACF work completely over the next 2 years. ${ }^{16}$ A recent qualitative study of Australian GP's perceptions identified poor remuneration, logistic issues, system inefficiencies and inadequate training as potential obstacles to treating older people in $\mathrm{ACF}^{17}$

Review of the relatively sparse literature published on Australian medical student attitudes toward older people found these to be measurably neutral to positive. Findings from qualitative research into student attitudes also captured by the review were mixed, with negative themes of nihilism, paternalism, communication challenge, perceptions of high morbidity and reduced quality of life. ${ }^{18}$ The reliability and validity of employing US-developed instruments to quantify Australian student attitudes is uncertain, as described in our critical review of these quantitative measures. ${ }^{19}$

To briefly summarise our review papers, the small number of Australian studies of medical student attitude to date have used either the University of California Los Angeles Geriatric Attitude Scale (UCLA-GAS) ${ }^{20}$ or the Ageing Semantic Differential (ASD). ${ }^{21}$ The UCLA-GAS is an explicit, statement-based survey, which has been criticised as measuring beliefs rather than attitudes, ${ }^{22}$ being unbalanced, with more negative (9) than positive (5) statements, ${ }^{23}$ and with lower internal reliability in studies conducted outside UCLA. ${ }^{23}{ }^{24}$ As with all explicit survey instruments, the UCLA-GAS may also be subject to response bias, where respondents choose more socially desirable options on the scales. The other widely used instrument for quantifying attitudes of medical students towards older people internationally is the ASD. The construct of semantic differential, where survey respondents indicate intensity and direction of their judgement of a social object on a scale of polar opposite adjectives, has advantages for measuring complex social stereotypes such as attitude. These include greater efficiency, ${ }^{25}$ more specificity for attitude than statement-based scales, lower likelihood of response bias and capacity for evaluation of attitudes within several dimensions/factors. ${ }^{26}$ Nonetheless, the ASD has several flaws rendering it suboptimal for use in Australian medical education research. It is an instrument reliant on words from the US lexicon of the $1950 \mathrm{~s},{ }^{21}$ some now ambiguous in meaning and/ or polarity, for example, the items liberal-conservative and ordinary-eccentric. The ASD is also unnecessarily repetitive of item pairs with similar meaning, has sexist origins and has questions concerning its factor structure. Our conclusion was that a 'fit for purpose' instrument for quantitative research of Australian medical student attitudes towards older people did not exist. ${ }^{19}$

Once we had identified a gap in the literature for a reliable, valid and contemporaneous measure of Australian medical student attitudes towards older people, the construct of semantic differential was adopted as most advantageous for development of the new survey instrument. Development of the AASD was contingent on contemporary Australian medical student language. The fundamental step was to obtain descriptive words for building anchors for the bipolar scales of the instrument, derived from qualitative study of words used to 


\section{Australian Ageing Semantic Differential}

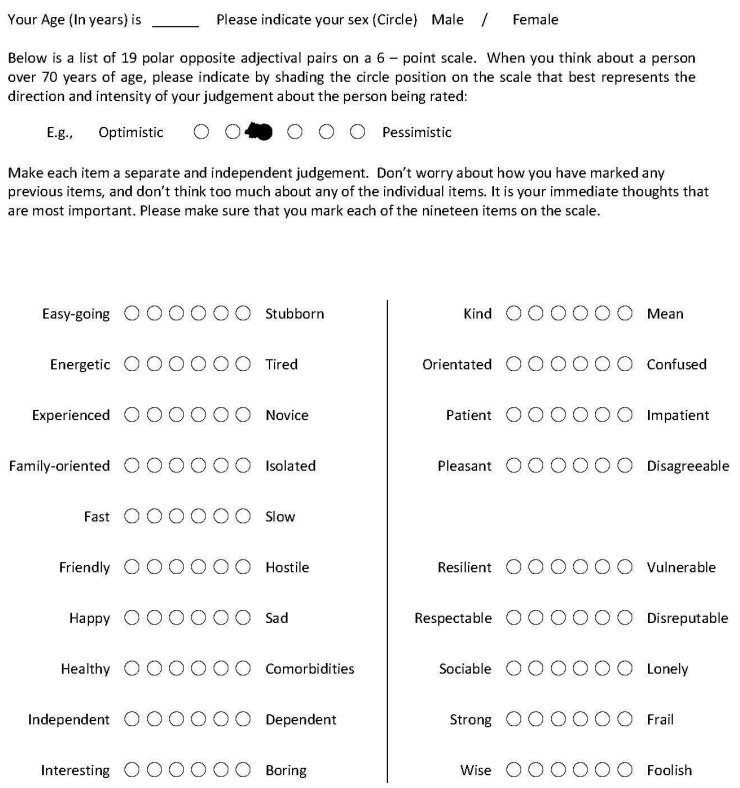

pooled data from this study of South Australian, Victorian and Western Australian medical students, together with data obtained from NSW students during the AASD developmental study, was subjected to descriptive statistical analysis.

\section{METHODS}

\section{Study design and date}

This study is based on the data obtained from a crosssectional survey using the AASD, conducted during 2018.

\section{Study procedures}

Geriatric education leads at medical schools in five states of Australia were asked for permission to recruit students from their respective school once approval was granted from the relevant institution's human ethics office. Three positive responses led to the final geographical footprint for data collection. When sufficient survey responses were obtained from surveying a convenient cluster of tutorial and lecture groups across the three states, further recruitment was ceased.

\section{Patient and public involvement}

Patients or the public were not involved in the design, or conduct, or reporting, or dissemination plans of our research.

\section{Setting}

Third-year medical students from the University of Figure 1 The Australian Ageing Semantic Differential.

describe older people by third-year medical students attending two Australian medical schools (The University of Sydney and University of Wollongong) in the state of NSW. The AASD scales were developed using an iterative approach. Pilot study of the prototype survey instrument was performed with third-year medical students attending the University of New South Wales medical school in late 2016, demonstrating internal reliability and usability for this instrument. ${ }^{27} \mathrm{~A}$ recently published paper describes further development of the AASD from data obtained from surveying students in three NSW medical schools. ${ }^{28}$ The AASD consists of 19 pairs of opposite adjectives, and can be viewed in figure 1 .

Our current study uses survey data obtained during 2018 from medical students in three states of Australia outside of NSW, to provide robust evidence, using confirmatory factor analysis (CFA), for a four-factor model of attitudes as measured by the AASD: Instrumentality (I), Personal Appeal (PA), Experience (E) and Sociability (S). We also aimed to demonstrate that the performance of the AASD instrument, as judged by internal consistency (Cronbach's alpha) and mean AASD and factor scores, was no different in an Australian student sample group from outside of NSW when compared with results from our previous survey of NSW medical students. Finally,

Melbourne (MU) and University of Western Australia (UWA) graduate programmes, and fourth-year undergraduate students from the University of Adelaide (UA). Students completing face-to-face tutorials or lectures were invited by way of a written participant information sheet to voluntarily complete the AASD survey following their lesson. As per ethics protocol, consent was considered given when respondents returned a completed form to the research assistant.

\section{Eligibility criteria}

Much of the research for development of the AASD has deliberately been conducted with third-year medical student participants. This has been because it is preferable to study attitudes once students have experienced clinical contact with older people during their respective medical courses. Australian medical education is either a 4-year graduate or 5-year or 6-year undergraduate programme. We wanted to sample students from both types of programmes; hence, third-year students in graduate programmes (MU and UWA) and fourth-year students in the longer undergraduate programme (UA) were eligible for recruitment. All Australian medical programmes incorporate general clinical rotations from at least second year. The timing of the surveys was unrelated to when students undertook specific geriatric medicine clinical rotations, which occur variably from school to school, and are not always mandatory. All surveys with 
an incomplete response to any scale were excluded from the data analysis.

\section{Sample}

In Australian medical schools, 17051 students were enrolled in 2018, with 11715 enrolled outside NSW. The aim was to survey Australian medical students across at least three states outside of NSW, obtaining a minimum sample size of 30 students from each state for comparison, together comprising a large enough sample for factor analysis. A total sample size of at least 100 was considered to be the minimum required, providing at least 5 subjects for each of the 19-item pairs (variables) in the AASD instrument, as recommended by Cohen et alfor educational research using factor analysis. ${ }^{29}$

\section{Measure}

The AASD used in the study was a self-administered, anonymised one-page semantic differential instrument, with 19 pairs of antonyms used to describe older people (see figure 1). Respondents were asked to shade in the circle on a 6-point scale for each of the item pairs, corresponding to their immediate attitudinal judgement concerning a person over 70 years of age, with 1 the lowest and 6 the most positive score. The developmental study employed three versions of the AASD, to test for any effects of response bias due to contextual contamination, an important step in the development of a semantic differential. ${ }^{25}$ As no response bias was detected, the final version of the AASD has positive adjectives on the left-hand side of the form, and negative adjectives on the right-hand side of the form. The most negative possible AASD attitudinal score is 19 and the most positive score is 114. An AASD score of 67 or greater is considered to indicate globally positive attitudes for the respondent.

Exploratory factor analysis (EFA) of NSW student survey data indicated a four-factor solution as preferred for the AASD. ${ }^{28}$ The four factors, in descending order of contribution to variance, are I, PA, E and S. We chose to retain two of the named factors from the original ASD: (1) I, with only 2 of the original 9 words kept ('strong' and 'healthy'), relating to the respondent's judgement of the perceived effectiveness or competency of an older person, and (2) PA, with 2 of the 14 original words retained ('pleasant' and 'friendly'). Thus, only 6 of 32 word pairs of the ASD are found within the AASD, with the new instrument using 13 new bipolar item pairs and introducing two new domains of attitude, $\mathrm{E}$ and $\mathrm{S}$. Scores for each of the four factors are not intended to be weighted. Factor (subscale) scores provide opportunity for investigation of the dimensionality of Australian medical student attitudes towards older people.

In addition, basic demographic data are obtained by the AASD instrument, with respondents asked to provide their age and sex.

\section{Analysis}

\section{Preliminary analysis}

Prior to conducting factor analysis, the Kaiser-MeyerOlkin (KMO) and Bartlett's tests of sampling adequacy were determined. KMO was 0.845 and Bartlett test of sphericity had a $\chi^{2}$ value of $1282.3(\mathrm{df}=171, \mathrm{p}<0.001)$, both indicating factorability of the data. All further analysis was conducted using IBM SPSS Statistics V.25 ${ }^{30}$ and IBM SPSS Amos V.25. ${ }^{31}$

\section{Confirmatory factor analysis}

CFA was performed to evaluate the fit of the original fourfactor AASD model with our new data. We performed four one-factor congeneric CFAs to measure that the covariance of the items in each of these factors are due to a common factor. In a previous study using EFA, we found support for four factors. The factors consisted of two composites with six items (I and PA), one composite with four items $(\mathrm{S})$ and one composite with three items (E) ${ }^{28}$ While a minimum of three items per factor has been recommended to reliably yield convergent solutions in $\mathrm{CFA},{ }^{32}$ a three-item factor will be a 'just identified' model with zero df. This leads to perfect model fit and as such is less ideal for testing theory. ${ }^{33}$ For this reason, we proposed to test the factor structure based on a minimum of four items per factor and made one change to the previous factor structure by including the item 'interesting' within the E factor instead of the PA factor, a decision influenced by high cross-loading noted for this item to both factors in the previously reported NSW study. ${ }^{28}$

Four congeneric CFAs were then conducted for each factor, and model fit was assessed. The I factor consisted of the items energetic, fast, healthy, independent, orientated and strong. The PA factor now consisted of five items, being easy-going, friendly, kind, patient and pleasant. The $\mathrm{E}$ factor consisted of four items: experienced, respectable, wise and interesting. The $\mathrm{S}$ factor consisted of items family-oriented, happy, sociable and resilient.

Five model fit statistics were used. The $\chi^{2}$ test assesses the fit by comparing the obtained sample correlation with the correlation matrix estimated under the model. Small $\chi^{2}$ values with $p>0.05$ indicates a good fit. The Comparative Fit Index (CFI) and Non-Normed Fit Index or TuckerLewis index (TLI) compare the hypothesised model to a null model. The CFI and TLI values of $\geq 0.95$ indicates a good fit. The root mean square error of approximation (RMSEA) and standardised root mean square residual (SRMR) reflect how close the model fits to a reasonably fitted model, and a good fit is indicated by values $\leq 0.06$ for the RMSEA and $\leq 0.09$ for SRMR. ${ }^{34} 35$

Internal consistency is a way to gauge how well a questionnaire or survey is measuring what you want it to measure. Reliability for the AASD will be determined through item analysis using Cronbach's alpha. Cronbach's alpha measures the internal consistency of a scale or how closely a set of items are as a group. Cronbach's alpha will be performed on each of the factors from the AASD, to ensure that individuals are responding 
consistently to items within each subscale. Cronbach's alpha of 0.60 is seen as adequate and Cronbach's alpha of 0.7 and above shows good reliability, indicating higher strength of consistency. ${ }^{36}$

\section{Descriptive statistics}

Mean total AASD scores and mean factor scores were obtained for the purpose of comparison of AASD survey measures of attitudes from this study in Victoria, Western Australia and South Australia $(\mathrm{n}=188)$ with the AASD total and factor attitudinal scores measured by the previous NSW developmental study ( $\mathrm{n}=321)$.

On confirming no significant difference in performance of the AASD instrument across Australian states, further statistical analysis was undertaken, comparing the data by institution, year of course, medical course type, gender and age, using the combined dataset obtained from surveying students in six institutions across four Australian states $(\mathrm{n}=509)$.

\section{RESULTS}

\section{Study sample}

Fully completed AASD survey responses were obtained from 188 medical students from states outside NSW, from a potential target group of 238 third or fourth years at three university medical schools; MU, UWA, and UA (response rate $=79 \%)$. Very few of the student survey responses were incomplete (4/238), and these were excluded from the analysis. Cronbach's alpha for the 19-item pair AASD was 0.84. Response rates and demographics of the student sample groups were similar to that in the development study conducted previously in NSW (see table 1).

\section{CFA}

Table 2 shows the fit indices for each of the four AASD composites from one-factor congeneric CFA (see below).

The AASD factors in an Analysis of a Moment Structures (AMOS) model may be viewed in the diagram provided as a supplement to the main article (see online supplementary file 1).

Table 3 shows the factor loadings of each of the items to the factors (see below).

The I factor items showed good fit with all five model fit indices, factor loadings for each item ranging from 0.57 to
Table 2 CFA model fit indices of AASD

\begin{tabular}{llllll}
\hline \multirow{2}{*}{ AASD factors } & \multicolumn{4}{l}{ Model fit indices } \\
\cline { 2 - 6 } & $\mathbf{X}^{\mathbf{2}}$ ( $\mathbf{p}$ value) & $\mathbf{C F I}$ & TLI & RMSEA & SRMR \\
\hline I & $11.5(0.24)$ & 0.99 & 0.99 & 0.04 & 0.03 \\
PA & $16.8(0.005)$ & 0.94 & 0.89 & 0.11 & 0.05 \\
E & $0.65(0.72)$ & 1.0 & 1.0 & 0.00 & 0.01 \\
S & $3.2(0.20)$ & 0.98 & 0.95 & 0.06 & 0.03 \\
\hline
\end{tabular}

AASD, Australian Ageing Semantic Differential; CFA, confirmatory factor analysis; CFI, Comparative Fit Index; E, Experience; I, Instrumentality; PA, Personal Appeal; RMSEA, root mean square error of approximation; S, Sociability; SRMR, standardised root mean square residual; TLI, Tucker-Lewis Index.

0.83. Model fit indices for the PA factor was only adequate. For this sample, the factor loading for the item patient was lowest at 0.37 , contributing only $14 \%$ to the variance of this latent factor. Model fit improves significantly when this item is dropped from this factor with $\chi^{2}=3.9(p=0.14)$, $\mathrm{CFI}=0.99$, TLI $=0.97$, RMSEA $=0.07$ and $\mathrm{SRMR}=0.03$. This factor with only four items can be considered as an alternative for this composite. The $\mathrm{E}$ factor with four items has excellent fit with all model fit indices, factor loadings ranging from 0.56 to 0.80 . The $\mathrm{S}$ factor also had good model fits in all five indices, with factor loadings ranging from 0.39 to 0.63 .

Cronbach's alpha results for each of the factors (subscales) were all satisfactory: $\mathrm{I}=0.84, \mathrm{PA}=0.71, \mathrm{E}=0.71$ and $\mathrm{S}=0.60$.

\section{Descriptive statistics}

All mean AASD survey scores by university medical schools were positive, as can be seen below in table 4 .

Comparison by independent t-testing of the mean AASD obtained from this survey of Victorian, West Australian and South Australian students with the mean AASD from NSW student surveys published previously revealed no difference $(\mathrm{t}(507)=0.584, \mathrm{p}=0.445)$.

There was no significant difference in mean AASD score for student groups surveyed at the six Australian medical schools sampled, as determined by one-way analysis of variance (ANOVA), $(F(5,503)=0.996, \mathrm{p}=0.42)$.

Table 1 Response rates and demographic characteristics of survey participants by Australian state

\begin{tabular}{|c|c|c|c|c|c|c|c|c|}
\hline \multirow{2}{*}{$\begin{array}{l}\text { Australian state } \\
\text { New South Wales (first-year and third- } \\
\text { year students) }\end{array}$} & \multirow{2}{*}{$\frac{\mathbf{N}}{321}$} & \multirow{2}{*}{$\begin{array}{l}\text { Completed } \\
\text { response rate } \\
(\%)\end{array}$} & \multicolumn{6}{|c|}{ Demographics } \\
\hline & & & \multicolumn{3}{|c|}{$\begin{array}{l}\text { Age (years) } \\
\text { Mean SD Range }\end{array}$} & \multicolumn{3}{|c|}{$\begin{array}{l}\text { Sex (\%) } \\
\text { Male Female Not giver }\end{array}$} \\
\hline Victoria (third-year students) & 106 & 75.7 & 24.0 & 1.5 & $22-29$ & 53.8 & 41.5 & 4.7 \\
\hline
\end{tabular}

${ }^{*}$ Data previously published. ${ }^{28}$ 
Table 3 Factor loadings of AASD composites by CFA

\section{Factors}

\begin{tabular}{|c|c|c|c|c|}
\hline \multirow[b]{2}{*}{ Item } & \\
\hline & I & PA & $\mathbf{E}$ & $\mathbf{S}$ \\
\hline Energetic & 0.57 & & & \\
\hline Fast & 0.76 & & & \\
\hline Healthy & 0.83 & & & \\
\hline Independent & 0.67 & & & \\
\hline Orientated & 0.65 & & & \\
\hline Strong & 0.62 & & & \\
\hline Easy-going & & 0.42 & & \\
\hline Friendly & & 0.75 & & \\
\hline Kind & & 0.78 & & \\
\hline Patient & & 0.37 & & \\
\hline Pleasant & & 0.65 & & \\
\hline Experience & & & 0.56 & \\
\hline Wise & & & 0.80 & \\
\hline Respectable & & & 0.56 & \\
\hline Interesting & & & 0.59 & \\
\hline Family-oriented & & & & 0.57 \\
\hline Happy & & & & 0.55 \\
\hline Sociable & & & & 0.63 \\
\hline Resilient & & & & 0.39 \\
\hline
\end{tabular}

AASD, Australian Ageing Semantic Differential; CFA, confirmatory factor analysis; E, Experience; I, Instrumentality; PA, Personal Appeal; S, Sociability.

There was no difference in mean factor subscores by institution or by year of the medical course, when measured by one-way ANOVA. In addition, there were no differences between undergraduate medical student and postgraduate medical student mean AASD scores and factor subscores by independent t-testing.

The data for mean total AASD and mean AASD factor scores by age and sex are provided in table 5 . There was no difference in total AASD mean scores by gender or age as determined by one-way ANOVA. The I factor had a slightly negative mean score overall. The mean scores for the three other factors were all positive. Female students had a significantly higher mean E score than male students and students not identifying gender, by one-way ANOVA $(F(2,506)=6.41, \mathrm{p}=0.002)$.

Student age was found to correlate with the I factor score, $r=012(p=0.008)$.

\section{DISCUSSION}

This study has provided robust evidence that the AASD as a measure of medical student attitudes towards older people is generalisable across both undergraduate and graduate medical programmes in Australia, and has performed with very good internal consistency in studies to date. As was demonstrated previously by the AASD developmental study findings from student surveys across three NSW medical schools (mean AASD score 73.2/114 and Cronbach's alpha=0.86), ${ }^{28}$ this study of medical students outside NSW has again demonstrated positive Australian medical student attitudes towards older people (mean AASD score 72.8/114 and Cronbach's alpha=0.84). Independent t-testing confirms no significant difference in mean AASD scores of students surveyed outside NSW when compared with their NSW counterparts.

Importantly, additional good evidence for reliability of the AASD scale in measuring attitudes of Australian medical students towards older people is provided by Cronbach's alpha values for each of the factors of the scale, which ranged from satisfactory $(S=0.60)$ to good ( $\mathrm{I}=0.84, \mathrm{PA}=0.71$ and $\mathrm{E}=0.71)$.

The four-factor structure of the AASD was demonstrated by CFA of survey data from this study to have acceptable indices of fit, providing evidence for the structural validity of this instrument. Additional evidence for AASD validity from this study builds on evidence for face validity provided by employment of contemporary Australian medical student language in construction of the instrument, as described in our earlier publications. ${ }^{27} 28$ There are two important points we would like to make in relation to the current AASD model of attitudes, to acknowledge potential areas of contention:

- We have chosen to relocate the item pair interesting-boring' within the E factor rather than the PA factor in our model for attitudes because significant

Table 4 Mean AASD scores for six Australian university medical schools

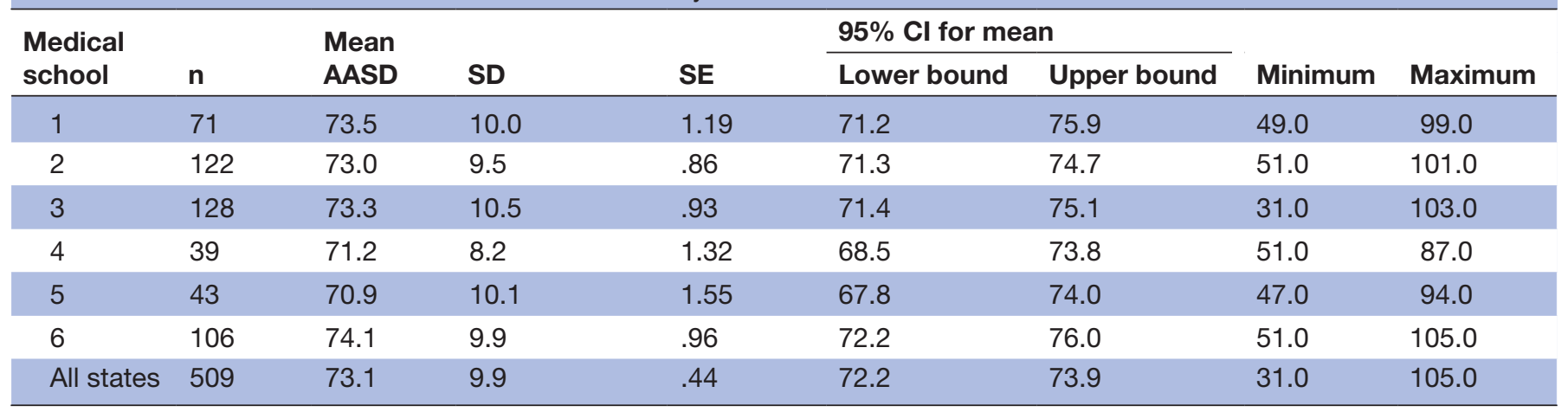


Table 5 Mean AASD factor and total scores by Australian medical student's age and sex

\begin{tabular}{llllll}
\hline & $\begin{array}{l}\text { I } \\
\text { mean (SD) }\end{array}$ & $\begin{array}{l}\text { PA } \\
\text { mean (SD) }\end{array}$ & S mean (SD) & $\begin{array}{l}\text { E } \\
\text { mean (SD) }\end{array}$ & $\begin{array}{l}\text { Total AASD } \\
\text { mean (SD) }\end{array}$ \\
\hline $\begin{array}{l}\text { Age: } 19-24 \text { years } \\
(n=318)\end{array}$ & $17.0(4.2)$ & $20.9(3.5)$ & $15.4(3.1)$ & $19.1(2.7)$ & $72.5(9.9)$ \\
\hline $\begin{array}{l}\text { Age: } 25-29 \text { years } \\
(n=140)\end{array}$ & $17.9(4.5)$ & $21.1(3.3)$ & $15.7(3.1)$ & $19.1(2.6)$ & $73.7(9.9)$ \\
$\begin{array}{l}\text { Age: } 30-34 \text { years } \\
(n=31)\end{array}$ & $19.5(3.8)$ & $21.8(2.8)$ & $16.3(2.3)$ & $19.4(2.6)$ & $77.1(8.5)$ \\
$\begin{array}{l}\text { Age: } 35+\text { years } \\
(n=12)\end{array}$ & $17.6(4.7)$ & $21.8(2.8)$ & $15.2(2.9)$ & $19.2(2.9)$ & $72.1(9.4)$ \\
$\begin{array}{l}\text { Age: } \text { not given } \\
(n=8)\end{array}$ & $18.6(3.2)$ & $19.9(4.1)$ & $14.3(2.8)$ & $17.4(2.3)$ & $71.0(9.8)$ \\
$\begin{array}{l}\text { Sex: } \text { male }(n=238) \\
\text { Sex: female }(n=230)\end{array}$ & $17.4(4.5)$ & $21.2(3.5)$ & $15.7(3.0)$ & $18.7(2.6)$ & $73.1(10.2)$ \\
\hline $\begin{array}{l}\text { Sex: not given } \\
(n=41)\end{array}$ & $17.4(4.2)$ & $20.8(3.4)$ & $15.5(3.0)$ & $19.6(2.6)$ & $73.3(9.5)$ \\
\hline
\end{tabular}

AASD, Australian Ageing Semantic Differential; E, Experience; I, Instrumentality; PA, Personal Appeal; S, Sociability.

cross-loading from this item to E and PA was noted in both the previously reported NSW study and the current study of students outside NSW. The other reason for this small change in factor model, as explained in the Methods section, is the desirability of having a minimum of four items loading to each factor. Finally, we feel that semantically the proposition that medical students consider how interesting older people are within an experience domain of attitudes is no more or less persuasive than a constructwhere students view older people who are interesting within a domain of PA.

- The other item pair which deserves mention is 'patient-impatient'. The indices of fit for items loading to PA improve significantly if 'patient' is removed from the AASD instrument. However, as mentioned above, all items in the AASD were derived from Australian medical student language, using an iterative process. Conceptually, and evident from item loading (see table 3), 'patient' fits within the PA factor of our model. We are thus comfortable leaving 'patient' within the existing factor model, accepting the likelihood that this item may well measure something else, perhaps E, in addition to PA.

There was no significant difference in mean total AASD and factor subscores by institution or between three different years (first, third and fourth) of the respective medical courses.

It is interesting that a decline in attitudes was not noted from first year to third year or fourth year, which is different to the finding from a recent longitudinal attitudes study conducted in the USA, where attitudes were found to worsen during the medical course. ${ }^{7}$ Care must be taken in interpreting our data in this regard, as it is based on a cross-sectional survey, and not as robust as the longitudinal cohort study. Also, numbers of older students and fourth-year students in our study were both relatively small. Ideally, a larger longitudinal Australian medical student cohort study is needed to clarify whether attitudes towards older people change during medical training in this country.

There was no significant difference according to whether the medical course was an undergraduate or graduate programme. In addition, there was no significant difference in mean AASD score by gender, whether the student was male, female or not indicating gender. Neither was there a significant difference in mean AASD score according to student's age.

For the Australian medical student group as a whole, mean PA and S factor scores were positive. There was no difference in mean scores for these factors by either gender or age.

While the mean $\mathrm{E}$ factor score was positive for the entire sample group, female students had significantly higher mean $\mathrm{E}$ factor scores than their male peers or students who did not identify gender. This gender difference in attitudes is consistent with some international literature, although the majority of published studies have demonstrated no measurable difference. ${ }^{37}$ Our results are similar to one Australian study of Australian hospital doctors, demonstrating gender disparity, with female doctors having more positive attitudes toward older people than male doctors. ${ }^{38}$ There is no previously published evidence for gender disparity in Australian medical students' attitudes towards older people. Further investigation is warranted to investigate the influence of gender on student attitudes towards older people.

Notably, over half of the participating students had negative views about the instrumentality, or effectiveness, of older people. These findings are congruent with what is known from the literature, that older people are often considered to be less 'competent'. ${ }^{3}$ Australian medical 
students surveyed were more likely to rate older people as tired, slow, having comorbidities and being frail. Medical educators should consider curriculum innovations, which emphasise to medical students that many older people are instrumental. Independence and high quality of life during healthy ageing, not disability and nihilism, should be considered normative, as promoted in regions with ageing populations such as Japan and Europe.$^{39} 40$ Exposure to healthy older people in the community during medical training should be incorporated within individual medical curricula. For some years, community placements with exposure to healthier older people ${ }^{41}$ or 'senior mentoring' ${ }^{42}{ }^{43}$ have been used successfully in medical education. A fundamental requirement of such curriculum innovations is high-quality contact between students and older people. ${ }^{37}$

Interestingly, our data show a mild positive correlation between medical student age and their I factor score. The weakness of this correlation may in part be due to the fact that the majority of medical students in our study were in a narrow age band between 19 years and 29 years of age, with only $10 \%$ of students 30 years of age or older. Nevertheless, this is the first study to describe a positive relationship between increasing Australian medical student age and positive attitudes towards the I factor (competency) of older people. This finding is consistent with general theories for ageism; young people prefer their own subculture as central to their social identities and the young fear their own mortality. ${ }^{38}$ A recent systematic review of international literature around medical studentsand doctorsattitudes towards older patients did not reveal any relationship between practitioner age and attitudes. ${ }^{37}$ However, British research has revealed that older medical students are more likely to have a positive attitude to caring for palliative care patients: 'When comparing age with attitudes it was found that increasing age was associated with a more positive view of being able to care as opposed to cure patients and a more positive view of listening to patients'. ${ }^{44}$ With an increasing trend for medicine to be taught as a graduate programme in Australia, and the average age of medical graduates increasing, it will be important to further investigate the relationship between medical student age and attitudes towards older people.

Quality and safety are mantra of modern medicine. Medical students are taught principles of quality primary care: access, continuity, comprehensiveness and coordination. ${ }^{45}$ While fundamental, these universal principles are insufficient. The Medical Board of Australia's code of conduct emphasises 'Good medical practice is patient centred ${ }^{46}{ }^{46}$ Gawande evocatively describes what this means for older people:

'...our most cruel failure in how we treat the sick and the aged is the failure to recognise that they have priorities beyond merely being safe and living longer; that the chance to shape one's story is essential to sustaining meaning in life; that we have the opportunity to refashion our institutions, our culture, and our conversations in ways that transform the possibilities for the last chapters of everyone's lives. ${ }^{47}$ (p243)

Optimising medical graduate attitudes towards care of older Australians should be a core learning outcome for every medical school. Thoughtful reflection on medical student attitudes towards older Australians and how these may be shaped, as well as our own attitudes as medical practitioners and powerful role models in medical education, should assist in breaking down ageist barriers erstwhile preventing access to both quality and personalised medical care.

\section{CONCLUSIONS}

Analysis of survey data obtained from students in attendance at six medical schools across four states in Australia has provided evidence for the structural validity, reliability and generalisability within Australia of the AASD survey instrument. For the first time, medical educators in Australia have access to a modern, 'purpose built' measure of student attitudes towards older people, with a four-factor model to investigate the dimensions of attitude in greater detail. As attitudes of students towards older people are a complex social stereotype and a multidimensional concept, qualitative investigation will need to be an important component of future research, complementing what is determined quantitatively by using the newly validated AASD. Longitudinal evolution of medical student attitudes, influence on future medical practice and career choice, and correlation with knowledge and skills, are all worth studying. Further research quantifying Australian medical student attitudes should investigate the influence of student's gender and age on attitudes. It will also be useful to study attitudes of medical graduates, particularly trainees in general practice and geriatric medicine, nascent medical professionals with whom most older Australians will consult in the future.

\section{Limitations}

Only medical school students from 6 of 19 Australian universities have thus far been surveyed using the AASD, from first, third and fourth years of the respective courses. Stronger evidence for the AASD four-factor model will become available as further research, preferably with a longitudinal cohort study, is conducted into the attitudes of Australian medical students towards older people. It is possible that evolution of the factor model may occur when more data becomes available, as will our understanding of the possible relationship between student gender or age and attitudes.

We chose not to test for convergent validity after the findings of our critical review of internationally available measures of medical student attitudes towards older people became available. We did not feel that the ASD and UCLA-GAS were reliable and sufficiently valid for use in the Australian setting. This of course means that 
we were unable to demonstrate the performance of the AASD in comparison with that of other internationally validated measures, a potential weakness in the evaluative process for the new instrument.

Test and retest with the same student group(s) has not been performed with the AASD. While there does not appear to be have been any attempt at this with the original ASD, it is recommended that test-retest is performed if there are concerns regarding the psychometric properties of the instrument being examined. ${ }^{25}$ Future research, including a component of test-retest, would improve the robustness of the evidence for test reliability, currently provided by good internal consistency for AASD data from both developmental and confirmatory studies.

\section{Author affiliations}

${ }^{1}$ Graduate Medicine, Faculty of Science Medicine and Health, University of Wollongong, Wollongong, New South Wales, Australia

${ }^{2} \mathrm{PhD}$ Candidate, Faculty of Medicine and Health, The University of Sydney, Sydney, New South Wales, Australia

${ }^{3}$ Australian Institute of Health Innovation, Macquarie University, Sydney, New South Wales, Australia

${ }^{4}$ Division of Rehabilitation and Aged Care, Hornsby Ku-ring-gai Health Service, Sydney, New South Wales, Australia

${ }^{5}$ Department of Health Care of Older People, Faculty of Medicine and Health, The University of Sydney, Sydney, New South Wales, Australia

Acknowledgements Thank you to Dr Alistair Lethbridge, University of Wollongong Graduate Medicine assessment officer, who assisted with the formatting of the AASD survey form. Thanks also to all geriatric medical education staff at the University of Adelaide, University of Melbourne, University of New South Wales, University of Sydney, University of Western Australia and University of Wollongong who provided practical assistance to make this study possible.

Contributors MW is the corresponding author and was responsible for $50 \%$ of the work in planning, conduct and write-up of the study. YT was responsible for $25 \%$ of the work in planning, statistical analysis and write-up of the study. SEK was responsible for $15 \%$ of the work in planning and write-up of the study. IW was responsible for $10 \%$ of the work in planning and write-up of the study.

Funding The authors have not declared a specific grant for this research from any funding agency in the public, commercial or not-for-profit sectors.

Competing interests None declared.

Patient consent for publication Not required.

Ethics approval Ethics permission to conduct this study was obtained from the Human Research Office of the University of Sydney (project number 2015/687).

Provenance and peer review Not commissioned; externally peer reviewed.

Data availability statement Data are available upon reasonable request. Data will be provided by the corresponding author upon reasonable request.

Open access This is an open access article distributed in accordance with the Creative Commons Attribution Non Commercial (CC BY-NC 4.0) license, which permits others to distribute, remix, adapt, build upon this work non-commercially, and license their derivative works on different terms, provided the original work is properly cited, appropriate credit is given, any changes made indicated, and the use is non-commercial. See: http://creativecommons.org/licenses/by-nc/4.0/.

ORCID iDs

Mark Wilson http://orcid.org/0000-0002-8135-4868

Yvonne Tran http://orcid.org/0000-0002-1741-4205

\section{REFERENCES}

1 Stall N. Time to end ageism in medical education. CMAJ 2012;184:728.

2 Australian Human Rights Commission. Human rights approach to ageing and health: respect and choice, 2012. Available: https:// www.humanrights.gov.au/sites/default/files/document/publication/ human_rights_framework_for_ageing_and_health.pdf [Accessed Oct 2018].

3 North MS, Fiske ST. An inconvenienced youth? Ageism and its potential intergenerational roots. Psychol Bull 2012;138:982-97.

4 COTA Victoria. Seniors rights Victoria. challenging Ageism, 2016. Available: https://cotavic.org.au/wp-content/uploads/2016/09/COTA Challenging_Ageism.pdf [Accessed Oct 2018].

5 Kusumastuti S, van Fenema E, Polman-van Stratum ECF, et al. When contact is not enough: affecting first year medical students' image towards older persons. PLoS One 2017;12:e0169977.

6 Samra R, Griffiths A, Cox T, et al. Medical students' and doctors' attitudes towards older patients and their care in hospital settings: a conceptualisation. Age Ageing 2015;44:776-83.

7 De Biasio JC, Parkas V, Soriano RP. Longitudinal assessment of medical student attitudes toward older people. Med Teach 2016;38:823-8.

8 Bodner E. On the origins of ageism among older and younger adults. Int Psychogeriatr 2009;21:1003-14.

9 Australian Institute for health and welfare, 2018. Available: https:// www.aihw.gov.au/reports/older-people/older-australia-at-a-glance/ contents/health-functioning [Accessed Oct 2018].

10 Steinert Y, Cruess RL, Cruess SR, et al. Faculty development as an instrument of change: a case study on teaching professionalism. Acad Med 2007;82:1057-64.

11 Lucchetti ALG, Lucchetti G, de Oliveira IN, et al. Experiencing aging or demystifying myths? - impact of different "geriatrics and gerontology" teaching strategies in first year medical students. BMC Med Educ 2017;17:35.

12 Hussain R, Kendig H, O'Loughlin K, et al. Perceptions of healthcare professionals' treatment of older people. Australas J Ageing 2017;36:102-6.

13 Minichiello V, Browne JAN, Kendig HAL. Perceptions and consequences of ageism: views of older people. Ageing Soc 2000;20:253-78.

14 Lewis GA, Pegram RW. Residential aged care and general practice: workforce demographic trends, 1984-2000. Med J Aust 2002;177:84-6.

15 Magin P, Catzikiris N, Tapley A, et al. Home visits and nursing home visits by early-career GPs: a cross-sectional study. Fam Pract 2017:34:77-82.

16 AMA aged care survey report, 2017. Available: https://ama.com. au/system/tdf/documents/2017\%20AMA\%20Aged\%20Care\% 20Survey\%20Report.pdf?file=1\&type=node\&id $=48948$

17 Pearson R, Mullan J, Ujvary E, et al. Australian general practitioner attitudes to residential aged care facility visiting. Health Soc Care Community 2018;26:e497-504.

18 Wilson MA, Kurrle SE, Wilson I. Understanding Australian medical student attitudes towards older people. Australas J Ageing 2018;37:93-8.

19 Wilson MAG, Kurrle S, Wilson I. Medical student attitudes towards older people: a critical review of quantitative measures. BMC Res Notes 2018;11:71.

20 Reuben DB, Lee M, Davis JW, et al. Development and validation of a geriatrics attitudes scale for primary care residents. J Am Geriatr Soc 1998;46:1425-30.

21 Rosencranz HA, McNevin TE. A factor analysis of attitudes toward the aged. Gerontologist 1969;9:55-9.

22 Intrieri RC, von Eye A, Kelly JA. The aging semantic differential: a confirmatory factor analysis. Gerontologist 1995;35:616-21.

23 Stewart TJ, Roberts E, Eleazer P, et al. Reliability and validity issues for two common measures of medical students' attitudes toward older adults. Educ Gerontol 2006;32:409-21.

24 Kishimoto M, Nagoshi M, Williams S, et al. Knowledge and attitudes about geriatrics of medical students, internal medicine residents, and geriatric medicine fellows. J Am Geriatr Soc 2005;53:99-102.

25 Verhagen T, Hooff B, Meents S, et al. Toward a better use of the semantic differential in is research: an integrative framework of suggested action. Journal of the Association for Information Systems 2015;16:108-43.

26 Osgood CE. The nature and measurement of meaning. Psychol Bull 1952;49:17:197-237.

27 Wilson M, Wilson I, Kurrle S. Development of the Australian ageing semantic differential, a new instrument for the measurement of medical student attitudes. Australas J Ageing 2018;38.

28 Wilson MAG, Tran Y, Wilson I, et al. Development of the Australian ageing semantic differential, a new instrument for measuring Australian medical student attitudes towards older people. Australas J Ageing 2019;38:1-8.

29 Cohen L, Manion L, Morrison K. Research methods in education. $7^{\text {th }}$ Edition. London \& New York: Routledge, 2011. 
30 SPSS statistics for windows version 25.0. Armonk, NY:IBM Corp; 2017.

31 Arbuckle JL. IBM SPSS. version 25.0. Chicago Amos; 2017.

32 Marsh HW, Hau KT, Balla JR, et al. Is more ever too much? the number of indicators per factor in confirmatory factor analysis. Multivariate Behav Res 1998;33:181-220.

33 Hair JF, Black WC, Babin BJ, et al. Multivariate data analysis. Upper Saddle River, NJ: Pearson, 2010.

34 Hooper D, Coughlan J, Mullen M. Structural equation modelling: guidelines for determining model fit. EJBRM 2007;6.

$35 \mathrm{Hu}$ Li-tze, Bentler PM. Cutoff criteria for fit indexes in covariance structure analysis: conventional criteria versus new alternatives. Structural Equation Modeling: A Multidisciplinary Journal 1999;6:1-55.

36 Taber KS. The use of Cronbach's alpha when developing and reporting research instruments in science education. Research in Science Education 2018;48:1273-96.

37 Samra R, Cox T, Gordon AL, et al. Factors related to medical students' and doctors' attitudes towards older patients: a systematic review. Age Ageing 2017;46:911-9.

38 Leung S, LoGiudice D, Schwarz J, et al. Hospital doctors' attitudes towards older people. Intern Med J 2011;41:308-14.

39 Arai $\mathrm{H}$, Ouchi $\mathrm{Y}$, Yokode $\mathrm{M}$, et al. Toward the realization of a better aged Society: messages from gerontology and geriatrics. Geriatr Gerontol Int 2012;12:16-22.
40 Boeckxstaens P, De Graaf P. Primary care and care for older persons: position paper of the European forum for primary care. Qual Prim Care 2011;19:369-89.

41 Wilkinson TJ, Gower S, Sainsbury R. The earlier, the better: the effect of early community contact on the attitudes of medical students to older people. Med Educ 2002;36:540-2.

42 Bernard MA, McAuley WJ, Belzer JA, et al. An evaluation of a lowintensity intervention to introduce medical students to healthy older people. J Am Geriatr Soc 2003;51:419-23.

43 Shue CK, McNeley K, Arnold L. Changing medical students' attitudes about older adults and future older patients. Acad Med 2005;80:S6-9.

44 Lloyd-Williams M, Dogra N. Caring for dying patients--what are the attitudes of medical students? Support Care Cancer 2003;11:18:696-9.

45 Starfield B, Shi L, Macinko J. Contribution of primary care to health systems and health. Milbank Q 2005;83:457-502.

46 Medical Board of Australia. Good medical practice: a code of conduct for doctors in Australia, 2014. Available: https://www. medicalboard.gov.au/Codes-Guidelines-Policies/Code-of-conduct. aspx [Accessed Oct 2018].

47 Gawande A. Being mortal. Illness, medicine, and what matters in the end. London: Profile Books, 2014. 